\title{
Application of oxygen enrichment in hot stoves and its potential influences on the energy system at an integrated steel plant
}

\author{
Chuan Wang, ${ }^{1, *}$, Jonny Karlsson ${ }^{2}$, Lawrence Hooey ${ }^{1,3}$, Axel Boden ${ }^{1}$ \\ ${ }^{1}$ Centre for process integration in steelmaking, Swerea MEFOS AB, 97125 Luleå, Sweden \\ ${ }^{2}$ SSAB EMEA, SE-97188 Luleå, Sweden \\ ${ }^{3}$ University of Oulu, PL 4000, 900014 Oulun Yliopisto, Finland (Adjunct Professor) \\ * Corresponding author. Tel: +46 920200223, Fax: +46 920255832, E-mail: chuan.wang@swerea.se
}

\begin{abstract}
The purpose of the presented paper is to investigate oxygen enrichment in hot stoves for an integrated steel plant. The application of oxygen enrichment in hot stoves will lead to lower coke or PCI rate by increased blast temperature. With oxygen enrichment, the high calorific value COG, could be saved while keeping the same blast temperature. Several alternatives of using the saved COG are presented. Furthermore, an analysis of how oxygen enrichment into hot stoves will have influence on the whole energy system has been carried out by means of an optimization model. Different strategies have been suggested to minimize the total energy consumption at the studied steel plant and the nearby CHP plant.
\end{abstract}

Keywords: Oxygen enrichment, Hot stoves, Blast furnace, Energy system

\section{Introduction}

In the process of iron-making, hot stoves (HS) are used to preheat air used in the blast furnace (BF). The preheated air is called hot blast. A higher blast temperature will lead to lower coke consumption in $\mathrm{BF}$ operation, hence, the energy consumption and $\mathrm{CO}_{2}$ emission from $\mathrm{BF}$ will be reduced. Hot stoves work as counter-current regenerative heat exchangers. Hot stoves typically use low calorific blast furnace gas (BFG) combined with higher calorific value coke oven gas (COG). BFG is generated from BF when producing hot metal. COG is a valuable fuel being high in hydrogen $\left(\mathrm{H}_{2}\right)$ and methane $\left(\mathrm{CH}_{4}\right)$. At an integrated steel plant, $\mathrm{COG}$ is often delivered from the coking plant.

Basically, using oxygen enrichment in the air for combustion in the hot stoves offers three advantages. First, the hot blast temperature may be increased due to higher flame temperature which reduces the blast furnace reductant consumption. Secondly, the lower volume of flue gas reduces the loss of sensible heat via the flue gas. Thirdly, COG or other higher value fuels could be used more effectively elsewhere.

The purpose of this paper is to investigate the application of oxygen enrichment in hot stoves and its potential influences to the total energy system at an integrated steel plant. This is done by performing calculations of mass and heat balance for the HS-BF system, and also by means of an optimization model.

In next section, the HS-BF system is described followed by the description of BF performance with oxygen enrichment in hot stoves. In section 4, an optimization model has been applied to present the potential influences on the total energy system of the studied steel plant and a nearby combined heat and power plant (CHP). Finally, in section 5 concluding remarks are made based on the presented work including some recommendations.

\section{Description of hot stove - blast furnace system}

The hot stove often includes two separate parts, a combustion chamber and a check chamber. They work as a counter-current regenerative heat exchanger. The fuel gas is first combusted 
in the combustion chamber. The flue gas passes through the check chamber and heats it up, then leaves the stack to the ambient. This progress is often called on-gas time. When the check chamber is fully heated up during on-gas time, the blast time is started. During the blast time, the cold blast is blown into the system in opposite cycle and is heated by the check chamber. It then passes through the combustion chamber. Before blowing into the blast furnace, it is often mixed with cold blast to get the required and stable hot blast temperature. BFG is a process gas with low calorific value. It has to be blended with COG to get a higher calorific value before entering the combustion chamber. After blending, the average heating value is around $4.3 \mathrm{MJ} / \mathrm{Nm}^{3}$.

Traditionally the combustion air is used in hot stoves for fuel combustion. For the studied plant, the hot blast produced is $254 \mathrm{kNm}^{3}$ per hour with a temperature of $1104{ }^{\circ} \mathrm{C}$, which is required by the blast furnace to produce hot metal with a production rate of 275 tonnes per hour during the reference period.

The combustion air can be enriched with gaseous oxygen, oxygen enrichment. Compared to traditional combustion, less $\mathrm{N}_{2}$ will be generated which will absorb less reaction heat from combustion. This will lead to a higher adiabatic flame temperature (AFT) with the same amount of fuel gas. As for the hot stove, therefore, a higher blast temperature can be achieved. On the other hand, the low caloric value fuel gas can also be combusted alone without mixing with any enrichment gas to get the same flame temperature with the use of oxygen enrichment instead. The common enrichment gases used at hot stoves are, for example COG, LPG or NG.

\section{BF performance with oxygen enrichment in hot stoves}

In the studied steel plant, the hot stoves are fuelled with BFG together with some amounts of COG. The calculations for oxygen enrichment in HS-BF system were carried out by using a spreadsheet model [1].
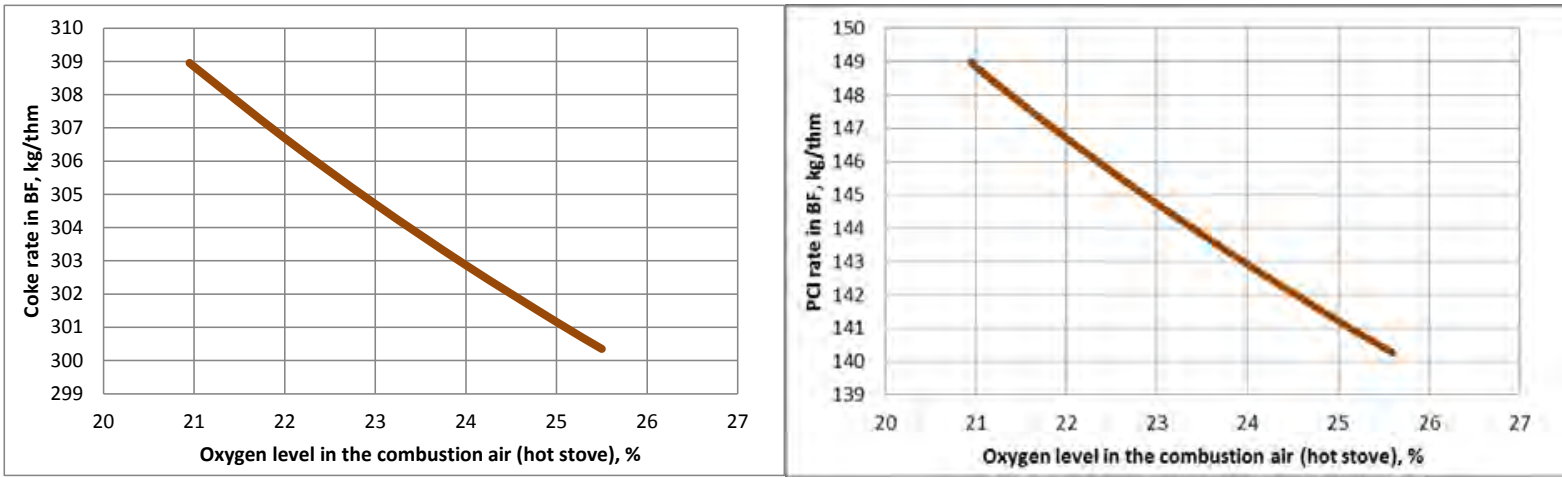

Fig. 1. The correlation between oxygen level in the air and coke rate (left) and PCI rate (right) in BF.

\subsection{Increased blast temperature with oxygen enrichment}

For the studied hot stoves, the hot blast temperature is assumed to increase to $1200{ }^{\circ} \mathrm{C}$ with the enriched oxygen in the combustion air. A higher hot blast temperature will lead to a lower reductant in the blast furnace. In the studied BF blast furnace, coke is used as reductant and charged from the top with other burden materials such as iron ore pellet and fluxes. Besides coke, pulverized coal (PCI) is also injection into BF via tuyers as fuel and reductant. Therefore, it's interesting to study the potential coke and PCI saving due to a higher hot blast temperature. Fig. 1 presents potential coke and PCI saving with enriched oxygen in the 
combustion air, which corresponds to $9.01 \mathrm{~kg}$ coke or $9.15 \mathrm{~kg}$ PCI with per ton hot metal per increased $100{ }^{\circ} \mathrm{C}$ blast temperature, respectively.

\subsection{COG saved with oxygen enrichment}

At a fixed blast temperature, increased oxygen level in the combustion air will lead to decreased COG flow in hot stoves, while BFG flow rate has to increase to provide enough energy, as shown in Fig.2. The high caloric value COG can be saved and used for other purpose.

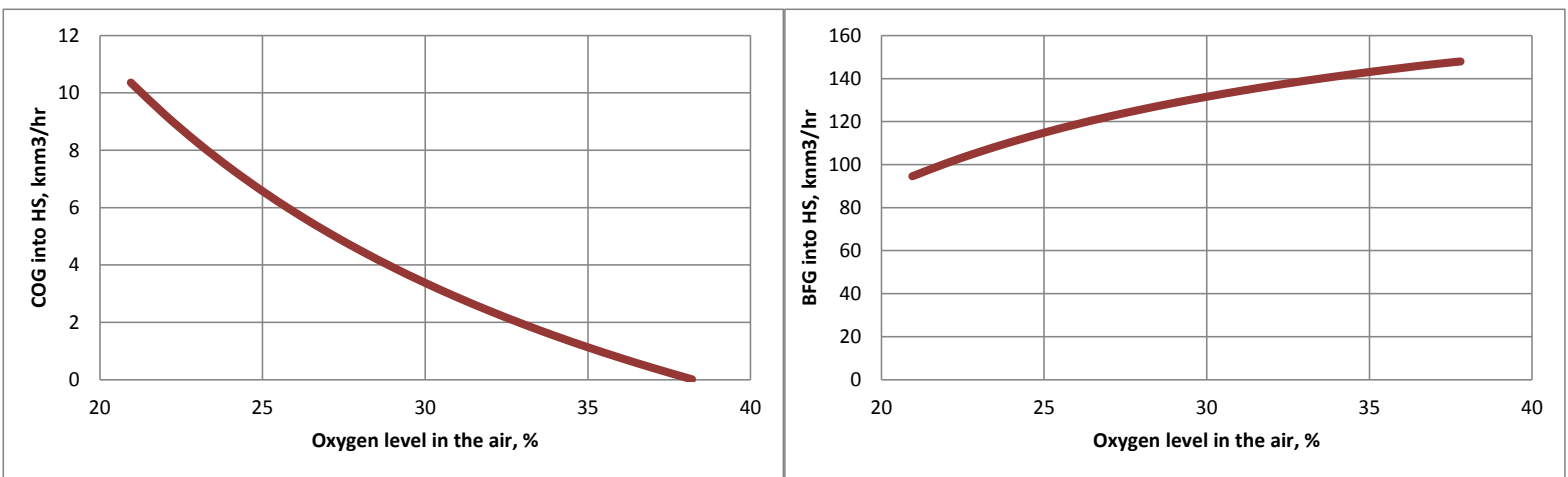

Fig.2. The correlation between oxygen level in the combustion air and COG (left) and BFG (right) flow in the hot stoves.

Previous studies showed that a lower reducant in BF could be achieved by injecting COG through tuyers [1-3]. Fig.3 shows the potential coke or PCI saving if saved COG in hot stoves instead is injected into BF via tuyers.
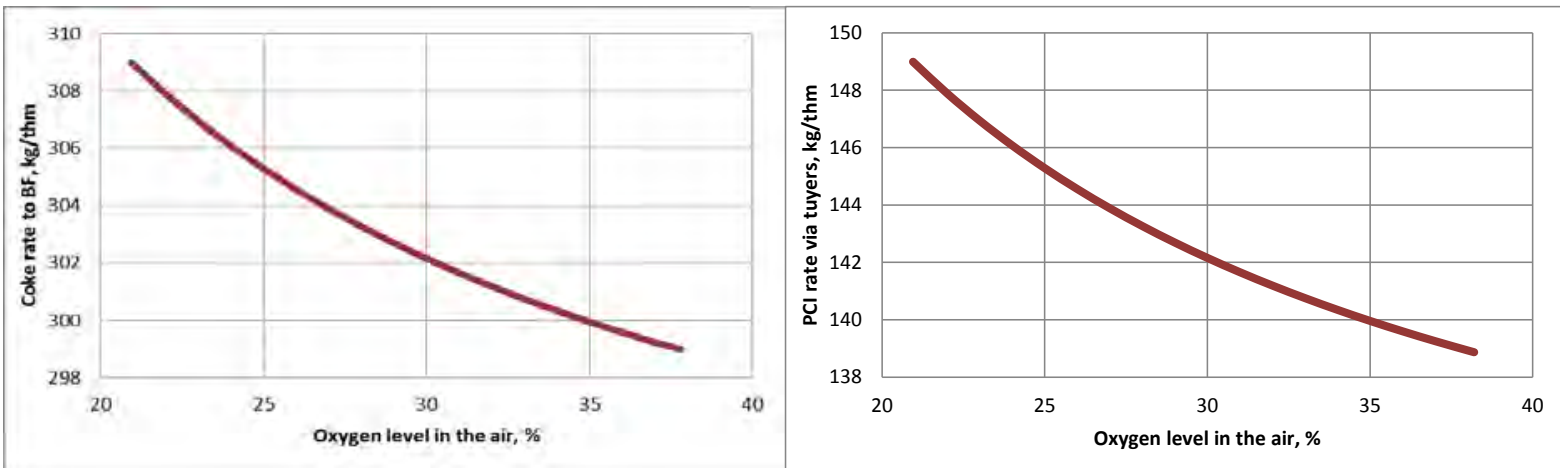

Fig.3. The correlation between oxygen level in the combustion air and coke and PCI rate in BF.

Table 1 gives a summary of key parameters for all scenarios discussed above. It's been noticed that a higher amount of BFG could be generated when COG is injected into BF via tuyers. At the same time, this will also lead to a higher heating value of BFG.

For the studied steel plant, there is another scenario to utilize the saved COG from the hot stove. That is to use it at the nearby combined heat and power (CHP) plant, which corresponds to Scenario 4 in Table 1. This will be presented in Section 4. 
Table 1. Key parameters in hot stove - blast furnace system for different scenarios.

\begin{tabular}{|c|c|c|c|c|c|c|c|}
\hline & Unit & Ref. case & Fixed COG_coke saving & Fixed COG_PCl saving & Fixed BLT_to PP & Fixed BLT_coke saving & Fixed BLT_PCl saving \\
\hline & Scenarios & Scenario 1 & Scenario 2 & Scenario 3 & Scenario 4 & Scenario 5 & Scenario 6 \\
\hline Coke & $\mathrm{kg} / \mathrm{thm}$ & 309.0 & 300.4 & 309.0 & 309.0 & 299.0 & 309.0 \\
\hline $\mathrm{PCl}$ & $\mathrm{kg} / \mathrm{thm}$ & 149.0 & 149.0 & 140.3 & 149.0 & 149.0 & 138.9 \\
\hline COG to BF via tuyers & $\mathrm{MJ} / \mathrm{thm}$ & 0.0 & 0.0 & 0.0 & 0.0 & 642.6 & 642.6 \\
\hline BFG generated & $\mathrm{knm} 3 /$ thm & 1.47 & 1.43 & 1.43 & 1.47 & 1.51 & 1.50 \\
\hline Heating value & $\mathrm{MJ} / \mathrm{Nm}^{3}$ & 2.97 & 2.97 & 2.96 & 2.97 & 3.08 & 3.07 \\
\hline Blast generated & $\mathrm{Nm}^{3} /$ thm & 924.2 & 886.5 & 885.5 & 924.2 & 917.7 & 916.4 \\
\hline Blast temperature & ${ }^{\circ} \mathrm{C}$ & 1104 & 1200 & 1200 & 1104 & 1104 & 1104 \\
\hline BFG consumed in HS & $\mathrm{nm}^{3} /$ thm & 332.9 & 358.2 & 358.6 & 332.9 & 524.7 & 525.5 \\
\hline COG consumed in HS & $\mathrm{MJ} / \mathrm{thm}$ & 642.6 & 642.6 & 642.6 & 0 & 0 & 0 \\
\hline $\mathrm{O}_{2}$ in combustion air & $\mathrm{Nm}^{3} /$ thm & 0 & 14.8 & 15.0 & 39.0 & 32.8 & 33.1 \\
\hline
\end{tabular}

\section{System analysis of the energy system in the studied steel plant}

The studied integrated steel plant consists of the following main process units: coking plant $(\mathrm{CP}) \rightarrow$ blast furnace (BF) $\rightarrow$ basic oxygen plant (BOF) $\rightarrow$ secondary metallurgy (SM) $\rightarrow$ continuous casting (CC). The final product is slab from CC. In addition, there are also some other process units, a lime kiln for lime production, an oxygen plant and a combined heat and power plant (CHP). All these process units are connected through material flows and a process gases network. Besides COG and BFG, there is also recovered process gas from the BOF, called basic oxygen furnace gas (BOFG). Fig. 4 shows the structure of the process gas network

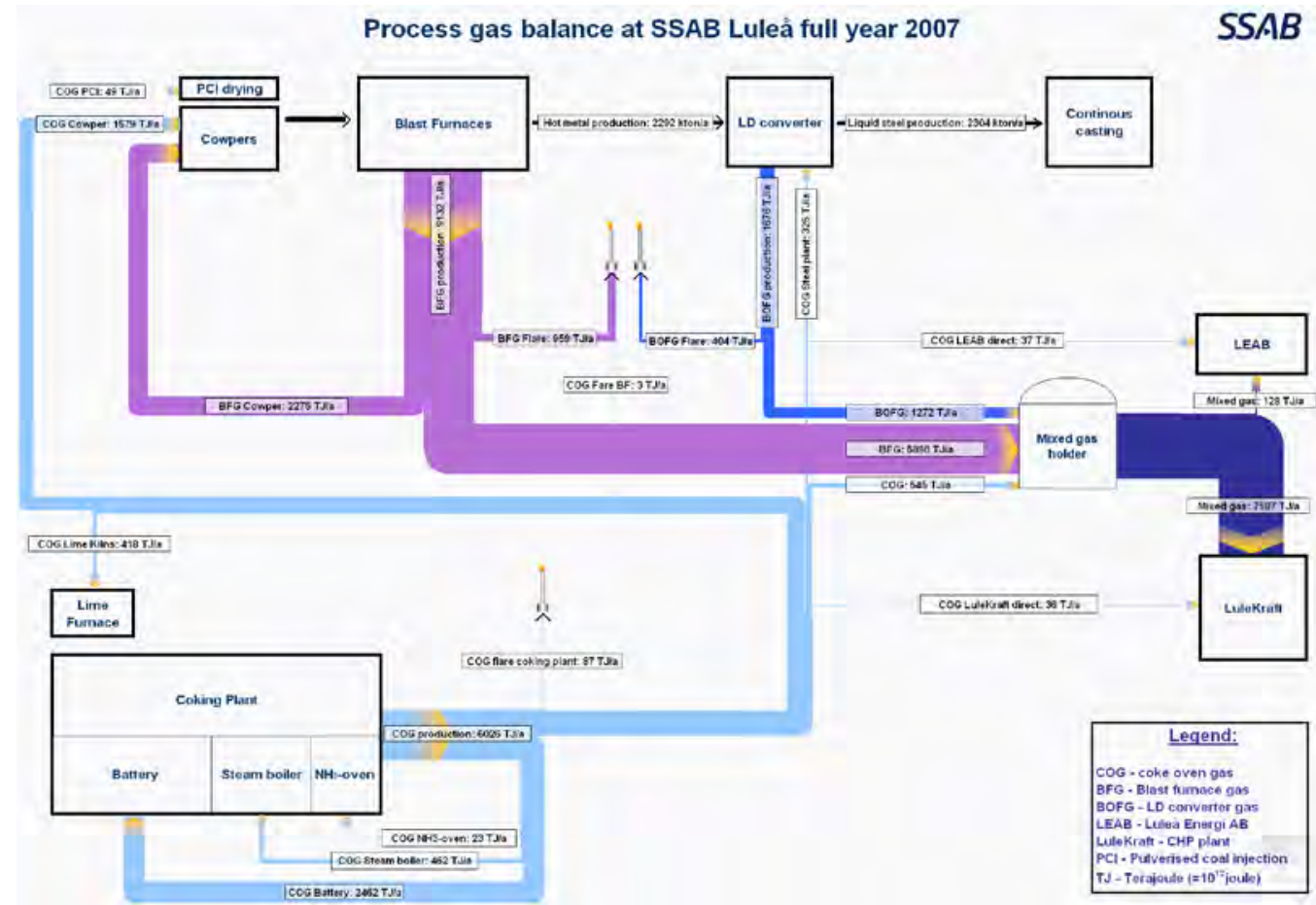

Fig. 4. The structure of process gas network at the studied plant

An optimization model has been applied to analyze the energy system in the studied steel plant. More details about the model can be read in previous publications [4-5]. The objective function set in the model is to minimize energy consumption for the total steel plant. There are two driving forces to run the model. The first is to produce the final product slabs, at 263 ton/hour as a year average. The second is to produce hot water at the CHP plant to the district heat network used by the nearby city. The CHP plant also produces electricity which is used at different process units within the plant. Therefore, it also provides electricity for oxygen 
production at the oxygen plant. When there is excess electricity generated from the CHP plant, the extra electricity is sold externally to the grid.

Before entering the CHP plant, the process gases of BFG, COG and BOFG are blended in the mix gas holder to get the required heating value and a stable gas flow before entering the boiler. Oil is used when heat load is higher or when there is lack of mixed gases. The electricity can be generated from the steam turbine by two different modules, a back pressure module and a condenser module, mainly depending on the heat demand from the district heat network. The alpha value of the back pressure module is $0.44\left(\alpha=\mathrm{P}_{\mathrm{el}} / \mathrm{P}_{\text {heat }}\right)$, and the electricity efficiency of the condenser module is 0.32 . The boiler efficiency, $\eta$, is 0.9 . In the model, the maximum fuel limitation for the boiler is 350MW, which is set by the regulation to control emissions, e.g. $\mathrm{NO}_{\mathrm{x}}, \mathrm{SO}_{\mathrm{x}}$ and $\mathrm{CO}_{2}$. The other limitation set for the boiler is the maximum flow rate of process gas, $90 \mathrm{Nm}^{3} / \mathrm{s}$.

Fig. 5 illustrates the heat demand curve versus the out-door temperature. As shown in the figure, the maximum heat supply from the CHP plant is $220 \mathrm{MW}$, and the minimum heat supply is $20 \mathrm{MW}$. When the out-door temperature varies in the internal of $[-18 ; 16]^{\circ} \mathrm{C}$, the heat demand curve can be linearized.

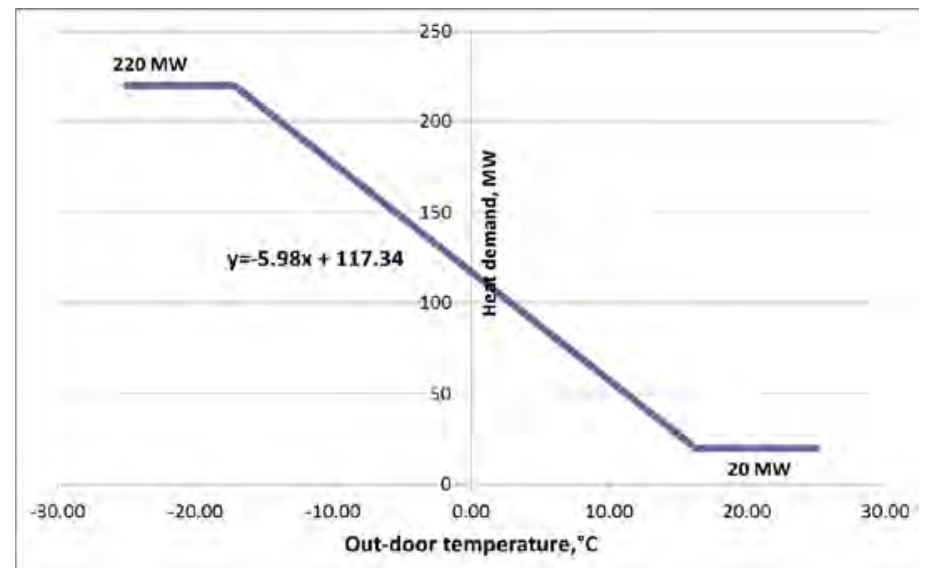

Fig.5.The correlation between out-door temperature and heat demand in the district heat network.

The optimization model is based on hourly data with a time span of one full year for the reference period. For example, the average heat demand is $85.7 \mathrm{MW}$, corresponding to an average out-door temperature of $5.3^{\circ} \mathrm{C}$. However, to illustrate how heat demand changes will have influence on the process gas network, the average value cannot be used because it varies with the seasonal out-door temperature especially in the Nordic region. Therefore, in this presented work 5 different values of heat demand are chosen: 20, 70, 120, 170 and 220MW respectively.

The model is set to run for the reference case and the optimized case to minimize the energy use for the total energy system. The energy content of the used energy carriers are presented in Table 2.

For the reference case, the model is run based on the operational data during the reference period to simulate for different heat demand levels. For the optimized case, the model will choose one scenario and combined scenarios listed in Table 1 (Scenario 1-6). Compared to the reference case, more freedoms are given in coal blending in the coke plant in the 
optimized case. Stable production is assumed, meaning there are no variations in each process unit, except for the CHP plant.

Table 2. Key parameters in hot stoves, GJ/ton.

\begin{tabular}{lclr}
\hline Energy carrier & Value & Energy carrier & Value \\
\hline TCMT petcoke coal & 35.9 & Bachatsky PCI coal & 28.7 \\
Peak downs coal & 29.6 & El Cerrejon PCI coal & 27.0 \\
Riverside coal & 29.3 & External coke & 40.9 \\
Massey powellton coal & 30.2 & PCI & 28.2 \\
Rocklick Eagle coal & 30.4 & Oil, GJ/MWh & 3.6 \\
Gonyella coal & 29.2 & Electricity, GJ/MWh & 3.6 \\
Gusare PCI coal & 28.2 & Flaring, GJ/unit & 1.0 \\
\hline
\end{tabular}

Fig. 6 shows the specific energy consumption (SEC) both for the reference and the optimized case. It indicates that a lower SEC will always be achieved in the optimized case. It's been found that BF behaviors in the optimized case are changing when heat demand is increasing at the CHP plant. The model prefers oxygen enrichment for COG saving to get the fixed BLT the same as the reference into BF. However, the way to use the saved COG varies between the scenarios of injecting into BF for coke saving (Scenario 5) and delivering to the CHP plant (Scenario 4) to avoid oil consumption in boiler. As indicated in Fig. 8 (right), before the heat demand is increased to $153.3 \mathrm{MW}$ which corresponds to an out-door temperature of $6^{\circ} \mathrm{C}$, BF will always be operated as Scenario 5. Scenario 4 starts when heat demand is greater than 153.3 MW. The percentage of Scenario 4 operation increases to $100 \%$ when the heat demand rises to $183.8 \mathrm{MW}$, meanwhile, operating of Scenario 5 decrease from $100 \%$ to $0 \%$. The model will keep running Scenario 4 when heat demand is higher than $183.8 \mathrm{MW}$ to get the minimum energy consumption.

The comparison between reference case and optimized case at a same level of heat demand may explain why minimum energy consumption could be achieved for the model. The following factors contribute for this. First in the coke plant, the coal blending is changed. In principle, the types of coal chosen are with lower volatile energy content. Lower volatile content coal will lead to a higher coke production rate, which will also lead to a lower amount of coking coal required in the coke batteries to produce the same amount of coke as the reference case. Thus, the energy consumption from the coke plant could keep as low as possible. Lower volatile type coal will generate less COG, consequently there will less COG to the CHP plant. However, this will compensate when saved COG from hot stoves instead is injected into BF to have a lower coke rate in BF. This has been proved when comparing the purchased coke amount between reference case and optimized case for example at the heat demand level of $20 \mathrm{MW}$. This solution will be kept the same until the heat demand is up to 153.3 MW at which point the model has to adopt a strategy of mixing Scenario 5 and Scenario 4 with a varying weighting ratio in order to keep the minimum energy consumption for the total energy system. At the point of $183.8 \mathrm{MW}$, the solution is completely switched to $100 \%$ of Scenario 4 because at such a high level heat demand it is more energy effective to use the saved COG in the CHP plant instead of injecting into BF and by that avoiding use of oil at the CHP plant. However, some amount of oil has to be used even in the optimized case when the heat demand is over $185.7 \mathrm{MW}$. 


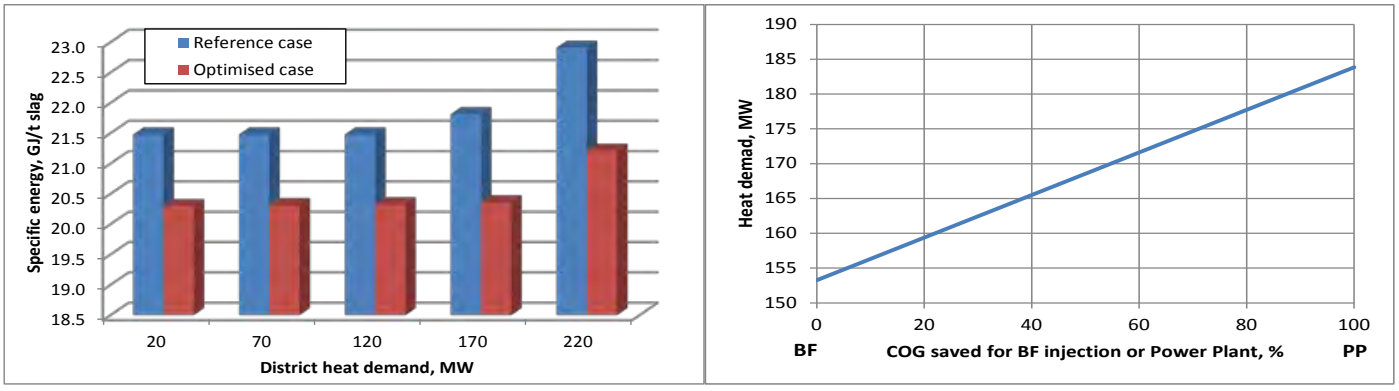

Fig.6. Left: Comparison of SEC between reference case and optimized case;

Right: BF behavior in the optimized case.

Fig. 7 illustrates the comparison of heat supply from the CHP between the reference case and the optimized case. It is found that oil will be replaced by COG in the optimized case at a high levels of heat demand. However, some amount of oil is still needed when the out-door temperature is lower than $-11^{\circ} \mathrm{C}$.
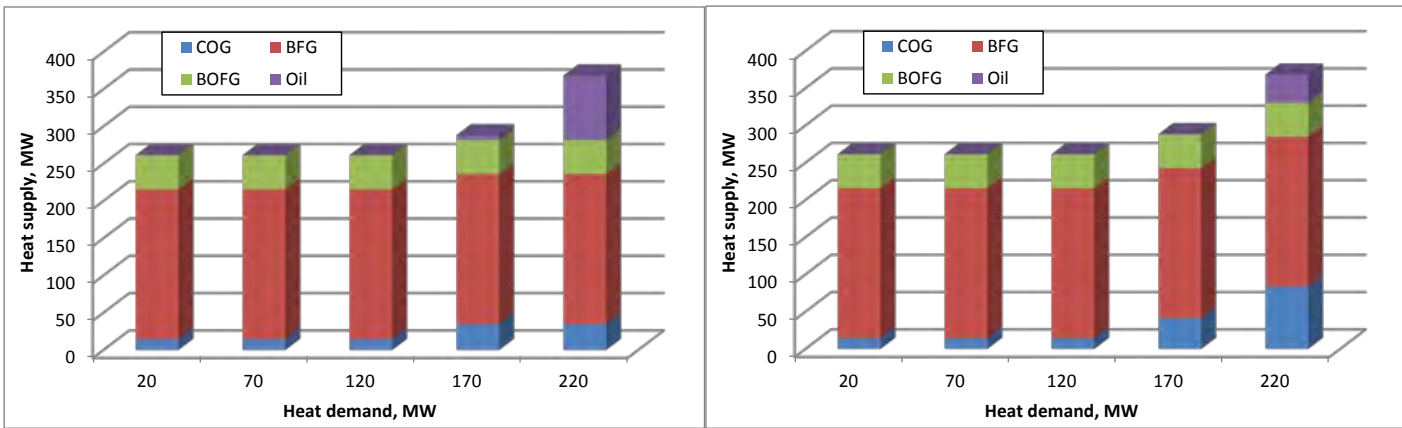

Fig.7. Left: Heat supply in the reference case; Right: Heat supply in the optimized case.

\section{Concluding remarks}

The presented work shows that the application of oxygen enrichment into hot stoves could lead to a lower coke or PCI rate in BF if the blast temperature is allowed to increase. High calorific value COG can also be saved by use of oxygen enrichment. Therefore, it is possible to use the saved COG in other process units. For the studied steel plant, the alternatives are, for example, inject COG into BF via tuyers or deliver it to the nearby CHP plant for district heat and electricity production. There are also other alternatives to use COG, such as at the reheating furnace in the rolling mill, or in the electric arc furnaces (EAF) to replace other fuels such as natural gas, LPG or oil. However, this depends on the site specific and is not applicable on the studied site.

An analysis of how oxygen enrichment into hot stoves will influence the total energy system has been carried out by means of an optimization model. Different strategies have been suggested from the model to achieve the minimum energy consumption for the studied steel plant and the nearby CHP plant.

The optimization made for the studied plant is to minimize the energy consumption for the total energy system. However, it does not mean that optimal solutions also are cost effective, which in fact is interesting to study.

In the current model, the availability of process gases and their flaring are set at a fixed value, based on hourly average value with a yearly time span. In addition, each process unit is assumed operating continuously and steadily. However, in reality there is normal varations. 
Therefore, it might be of importance to take these factors into account for energy system optimization.

As for the CHP plant, only a few heat demand corresponding to a few out-door temperatures, are included in this optimization work. The performance of CHP plant, such as heat loads curve, is therefore limited. Solution space based optimization can provide a better resolution for the studied energy system [6].

The HS-BF system is a very important part in the optimization model, and it's also the most complicated process unit in an integrated steel plant with the BF-BOF route. The mass and energy balance for HS-BF system are first carried out in a spreadsheet, key operating parameters generated from the spreadsheet then put into the HS-BF sub-model of the optimization model. Different operating conditions generate a list of key operating parameters as input to the model. Thus, the optimal solution from this sub-model can either be one case or a mixed case. This, however, may lead to less dynamic. For instance, the model only shows the oxygen amount into hot stoves at which COG will be fully substituted by BFG. What happen in between oxygen enrichment starting and maximum level cannot be predicted in model. Therefore, it could not show the results if the optimum level of oxygen enrichment is in between when modeling the total energy system although it may not be the case. Further model improvement in HS-BF system is needed towards a dynamic response.

\section{Acknowledgements}

We would like to thank the Centre for Process Integration in Steelmaking (PRISMA) and SSAB EMEA for the possibility to present this work. PRISMA is an Institute Excellence Centre supported by the Swedish Agency for Innovation Systems, the Knowledge Foundation, and eight industrial partners within the iron- and steel industry.

\section{References}

[1] P. Hooey, A. Boden, C. Wang, C. Grip and B. Jansson. Design and application of a spreadsheet-based model of the blast furnace factory, ISIJ International 50(7), 2010, pp. 924-930.

[2] A. Babich, S. Yaroshevskii, A. Formoso, A. Cores, L. Garcia and V. Nozdrachev. Coinjection of Noncoking Coal and Natural Gas in Blast furnace. ISIJ International 39 (3), 1999, pp. 229-238.

[3] J.C. Agarwal, F.C.Brown, D.L. Chin and G.S. Stevens, Results of Ultra High Rates of Natural Gas Injection into the Blast Furnace at Acme Steel Company, ISCTI/Ironmaking Conference Proceedings 57, 1998, 443-461.

[4] M. Larsson and J. Dahl, Reduction of the specific energy use in an integrated steel plant the effect of an optimization model, ISIJ International 43, 2003, pp. 1664-1673.

[5] C. Wang, C. Ryman, Larsson M, Wikström J-O and Grip C-E. A model on $\mathrm{CO}_{2}$ emission reduction in integrated steelmaking by optimization methods. International Journal of Energy Research 32, 2008, pp.1092-1106.

[6] J. Sandberg, M. Larsson, C. Wang, S. Lahti and J. Dahl. Solution space based optimization for increased resolution in energy system modeling, 2010, Manuscript to be submitted. 